\title{
Investigating the contribution of geometry on the failure of cellular core structures obtained by additive manufacturing
}

\author{
Hugo Araújo \\ IDMEC, Instituto Superior Técnico, Universidade de Lisboa, 1049-001Lisboa, Portugal \\ bugo.a.aranj093@gmail.com
}

Marco Leite

UNIDEMI, Departamento de Engenharia Mecânica e Industrial, Faculty of Science and Technology, New University of Lisbon, Portugal

Ma.leite@fct.unl.pt, bttp:/ / orcid.org/0000-0002-0319-4475

\author{
A.M.R. Ribeiro \\ IDMEC, Instituto Superior Técnico, Universidade de Lisboa, 1049-001Lisboa, Portugal \\ relogio.ribeiro@tecnico.ulisboa.pt_bttp://orcid.org/0000-0002-7848-6552
}

\author{
Augusto M. Deus \\ CEFEMA, Instituto Superior Técnico, Universidade de Lisboa, Lisboa, Portugal \\ amd@tecnico.ulisboa.pt, bttp:/ /orcid.org/0000-0002-0451-6245
}

Luis Reis, M.F. Vaz

IDMEC, Instituto Superior Técnico, Universidade de Lisboa, 1049-001Lisboa, Portugal

luis.g.reis@tecnico.ulisboa.pt,bttp:/ / orcid.org/0000-0001-9848-9569

fatima.vaz@tecnico.ulisboa.pt, bttp:/ / orcid.org/0000-0003-1629-523X

ABSTRACT. The aim of this work is to evaluate the mechanical properties and
failure analysis of cellular core structures with different geometries that were
obtained by additive manufacturing.
Sandwich panels are widely used in the aerospace and automotive industry. In
general, the core of the panels is made of a two dimensional cellular with a
honeycomb geometry. With the development of additive manufacturing
methods it is possible to produce samples with complex geometries which
may compete with conventional designs.
Thus an investigation was conducted to evaluate the mechanical behavior of
three core geometries, specifically, regular honeycombs, lotus and hexagonal
honeycombs with Plateau borders. Samples were produced in PLA (polylactic
acid) by fused deposition modelling (FDM). Experimental compressive
loading in three different directions, and finite element simulations of the
samples permit to evaluate their deformation and failure mechanisms.

\section{OPEN ACCESS}

Citation: Araújo, H., Leite, M., Ribeiro A.M.R,., Deus, A.M, Reis, L., Vaz, M.F., The Investigating the contribution of geometry on the failure of cellular core structures obtained by additive manufacturing, Frattura ed Integrità Strutturale, 49 (2019) 478-486.

Received: 14.01 .2019

Accepted: 23.05.2019

Published: 01.07.2019

Copyright: (C) 2019 This is an open access article under the terms of the CC-BY 4.0, which permits unrestricted use, distribution, and reproduction in any medium, provided the original author and source are credited. 
Load direction angles were found to have a strong influence in the failure mode.

Among the three structures, and for the same relative density, the lotus geometry exhibited the highest stiffness and strength. However, the absorbed energy was found to be higher for honeycomb, at two loading directions.

Some of the structures studied may be alternative to conventional designs pursuing the strategy of design with low weight and high strength.

KEYWORDS. Cores of sandwich composites; Mechanical properties; Additive Manufacturing; Fused deposition modelling; Finite element method.

\section{INTRODUCTION}

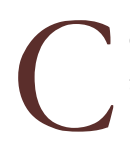
omposite cellular panels are of great potential in the field of transportation, automotive and aerospace industries, among others [1-7]. The main advantages of composites are their high strength-to-weight ratio, as well as, high stiffness-to-weight ratio. Sandwich panels are made of two skin sheets and a thicker core in between. The core may be a three dimensional material or a two dimensional cellular structure, which, in general, has a regular honeycomb geometry. The role of the honeycomb structure in the sandwich panels is to provide low density, high strength, high stiffness and capacity to absorb impact energy [1,5]. The mechanical response and failure behaviour of sandwich panels under different loading conditions has been extensively investigated [8-14].

Nevertheless, two dimensional cellular structures reveal, in-plane, lower stiffness and strength in comparison with the outplane behaviour. Although regular hexagonal arrangements are the most common geometries to be used in honeycomb panels, research has also focussed on new designs for the enhancement of in-plane properties [15]. There have been several experimental and numerical studies on the behaviour of sandwich structures with different core topologies which include honeycombs with corrugated walls [16,17], with ceramic tiles [18], auxetic cores [15,19], egg-box structures [7,20], truss cores [21,22], and other core designs, such as the ones studied by Araújo et al [23]. These authors [23] introduced three core designs for sandwich composite structures based on topologies proposed by Ronan et al.[24]. Taking advantages of additive manufacturing methods, plates with different relative densities were fabricated and the bending behaviour was evaluated [23].

In fact, the development of advanced manufacturing methods enable to produce new structures and complex shapes, which were restricted with more conventional manufacturing processes [21]. Fused deposition modelling (FDM) is by far the most common method of additive manufacturing processes [9,25-27]. In FDM, a filament of the material is conducted to a heated extruder, which leads to a nozzle, which moves controlled by numerical control software. A piece is obtained after cooling the semi-melted material which was deposited layer by layer. Several polymeric materials may be used in FDM, such as, PMMA (poly(methyl methacrylate)), PCL (poly(ecaprolactone)), PLGA (poly(lactidecoglycolide)), ABS (acrylonitrile butadiene styrene), and PLA (polylactic acid) [28-31]. PLA has a wide range of applications from the biomedical field to food packaging and consists in a biodegradable aliphatic polyester [32].

The emphasis of the present work is on the study of the in-plane properties measured under compression of three core designs, specifically, hexagonal honeycomb, lotus material and hexagonal honeycomb with Plateau borders, which may be used for sandwich core panels. Although these new core designs were previously studied under bending loading conditions by the present authors [23], the in-plane properties were not previously addressed. Three in-plane loading directions making angles of $0^{\circ}, 90^{\circ}$ and $45^{\circ}$ with the cell axis were taken into account. Finite element simulations were conducted and the numerical results were compared with the experimental behaviour of PLA samples produced by FDM. It was found that the deformation and failure of the several geometries depends, mainly on the loading direction.

\section{MATERIALS AND METHODS}

\section{Materials}

7 he CAD program Solidworks (SolidWorks, 2002) was used to generate the samples. Fig. 1 shows the three geometric arrangements studied, hexagonal honeycomb, lotus and hexagonal honeycomb with Plateau borders. The parameters 1 and $\mathrm{t}$ were maintained for the three structures, as $1=11.26 \mathrm{~mm}$ and $\mathrm{t}=2.31 \mathrm{~mm}$. In the lotus 
structure the radius was taken as $\mathrm{R}=8.66 \mathrm{~mm}$. The radius of the Plateau border was established as $\mathrm{r}=0.4 \times 1$ in the Plateau geometry.

In cellular solids, it is usual to define the relative density $\bar{\rho}$ as the ratio between the cellular material density and the density of the cell wall material [1], being a measure of the solid fraction. The relative densities given in Tab. 1 were calculated by specific equations for the mentioned configurations [24]. As the parameters 1 and $t$ were kept constant in the three structures, the relative densities of the three structures have similar values (Tab. 1).

The three structures were made with the same number of cells and dimensions around $118 \times 136 \times 10 \mathrm{~mm}$. In order to study the response in three loading directions, cellular structures were drawn with cell axis, $\mathrm{x}$, making angles of at $0^{\circ}$, at $90^{\circ}$ and at $45^{\circ}$ angles, with the direction of the axis $\mathrm{X}_{1}$ (Fig. 1).

The geometries will be designated by the geometry type, Honeycomb, Lotus and Plateau, followed by 0,90 or 45 , which correspond to the angle between $\mathrm{x}$ and $\mathrm{X}_{1}$. Overall, nine distinct structures were evaluated. Examples of the configurations Lotus_0, Lotus_45 and Lotus_90 are given in Fig. 2.

After being processed by the software CURA, the samples were fabricated in an Ultimaker 3 machine, using PLA purchased to ESUN. The temperature of extrusion and layer thickness were taken as $210^{\circ} \mathrm{C}$ and $0.1 \mathrm{~mm}$, respectively.

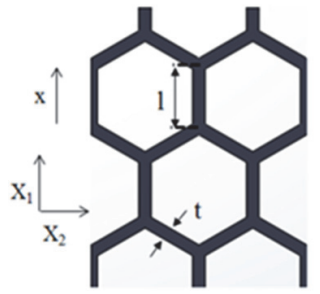

a)

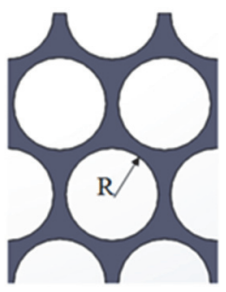

b)

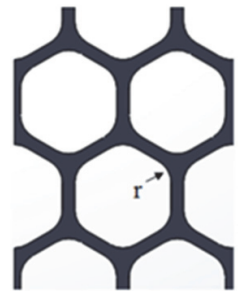

c)

Figure 1: Cells of a) regular hexagonal honeycomb, b) lotus material, and c) hexagonal honeycomb with Plateau borders of radius $\mathrm{r}=$ $0.4 \times 1$ (and relative density $\bar{\rho} \approx 0.2$ ).

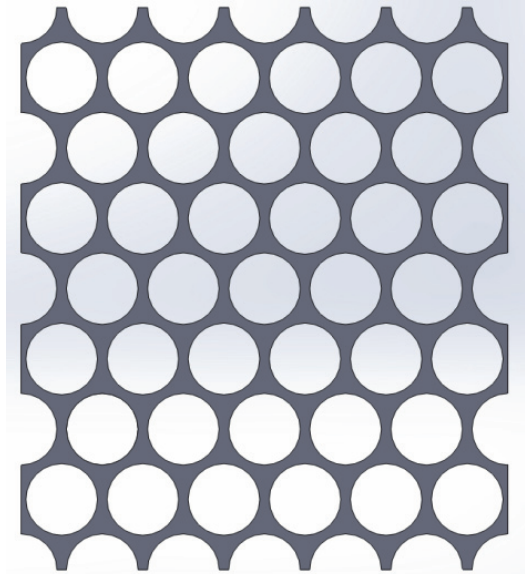

a)

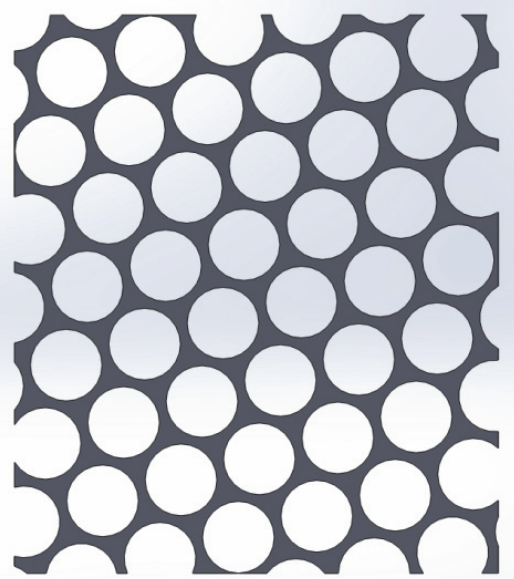

b)

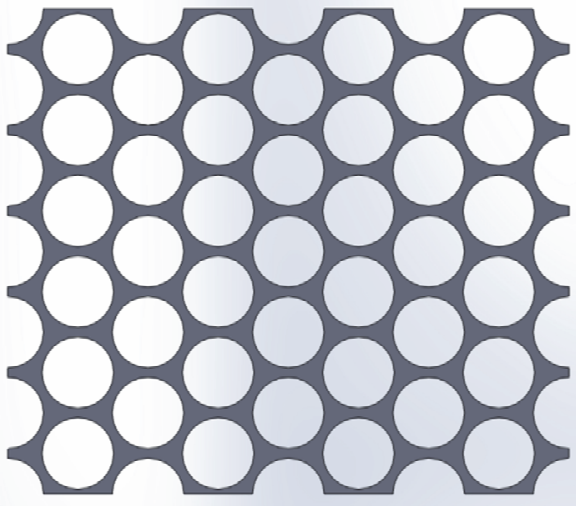

c)

Figure 2: Configuration of the lotus type with different angles between $\mathrm{x}$ and $\mathrm{X}_{1}$. a) Lotus_0, b) Lotus_45, and c) Lotus_90.

\section{Experimental tests}

The mechanical compressive tests were conducted in an Instron 3369 universal testing machine. A load cell of $10 \mathrm{kN}$ and a cross-head speed of $5 \mathrm{~mm} / \mathrm{min}$ were used. The Bluehill Software allowed obtaining the load-displacement data. The maximum or yield values of stress $\sigma_{Y}$, and correspondent strain $\varepsilon_{Y}$, the slope of the linear region of load-displacement curve, $\mathrm{K}$, and the energy $\mathrm{E}_{\mathrm{y}}$ until yield, were achieved. The energy $\mathrm{E}_{\mathrm{y}}$ was taken as the area of the curve until the yielding point, while the yield strain was determined dividing the yield displacement by the length of the specimen. The yield stress was calculated dividing the maximum load by the nominal contacting area between the plate and the specimen. The maximum stress was used to evaluate the strength, while the stiffness was assessed by the slope of the linear region of load-displacement curve. 


\section{Finite element modelling}

A finite element (FE) model was developed with ABAQUS software, version 6.16, with the purpose of studying the failure mechanisms of the structure under uniaxial compression and to compare with the experimental data.

The compression test was modelled with the cellular structure maintained between two parallel plates. One plate was fixed and the other plate was moving with constant velocity of $5 \mathrm{~mm} / \mathrm{min}$. The final displacement was fixed at $10 \mathrm{~mm}$ for all the tests. A contact interaction with a friction coefficient of 0.2 was chosen.

The cell-wall material was taken to be elastic-plastic. The properties of the PLA material used, namely density, Young's modulus, Poisson's ratio and yield stress, were set as $\rho_{\mathrm{s}}=1252 \mathrm{~kg} / \mathrm{m}^{3}, \mathrm{E}=1.5 \mathrm{GPa}, v=0.36$ and $\sigma_{\mathrm{ys}}=20 \mathrm{MPa}$, obtained from previous works [33]. Elements of type C3D20R, i.e., 20-node quadratic brick, reduced integration were used in the cell wall mesh.

The mesh quality was assessed through convergence tests of the FE models. The convergence criterion was defined as less than $7 \%$ changes in the highest von Mises stress.

The reaction force of the upper support was recorded and plotted in function of the support displacement.

\section{RESULTS AND DISCUSSION}

$\mathrm{F}$ ig. 3 presents the PLA failed structures that were subjected to experimental compressive tests. Figs. 3a)-c) exhibit the geometries Honeycomb_0, Lotus_0 and Plateau_0. Figs. 3d)-e) show the configurations Honeycomb_45, Lotus_45 and Plateau_45. The geometries Honeycomb_90, Lotus_90 and Plateau_90 are presented at Figs. 3g)-i). Fig. 4 shows the load-displacement curves obtained for all the compression experiments. The parameters assessed from the experimental tests, namely the yield stress $\sigma_{Y}$, the yield strain $\varepsilon_{Y}$, the slope of the linear region of load-displacement curve, $\mathrm{K}$, and the energy $\mathrm{E}_{\mathrm{y}}$ until yield, are indicated in Tab. 1 . The parameters $\sigma_{Y}, \mathrm{~K}$ and $\mathrm{E}_{\mathrm{y}}$ were normalized with respect to the relative density.

\begin{tabular}{lccccc}
\hline Geometry & $\bar{\rho}$ & $\sigma_{Y} / \bar{\rho}(\mathrm{MPa})$ & $\varepsilon_{Y}(\mathrm{~mm} / \mathrm{mm})$ & $\mathrm{K} / \bar{\rho}(\mathrm{N} / \mathrm{mm})$ & $\mathrm{E}_{\mathrm{y}} / \bar{\rho}(\mathrm{J})$ \\
Honeycomb_0 & 0.22 & 2.20 & 0.046 & 2553 & 36.95 \\
Lotus_0 & 0.28 & 4.37 & 0.027 & 5294 & 34.10 \\
Plateau_0 & 0.24 & 2.98 & 0.037 & 3542 & 36.12 \\
Honeycomb_45 & 0.22 & 0.93 & 0.037 & 1638 & 12.59 \\
Lotus_45 & 0.28 & 1.20 & 0.026 & 2451 & 9.07 \\
Plateau_45 & 0.24 & 1.01 & 0.035 & 1973 & 12.00 \\
Honeycomb_90 & 0.22 & 1.22 & 0.038 & 1962 & 17.18 \\
Lotus_90 & 0.28 & 2.64 & 0.034 & 4653 & 26.57 \\
Plateau_90 & 0.24 & 1.46 & 0.033 & 3082 & 16.58 \\
\hline
\end{tabular}

Table 1: Relative density and experimental compression results.

When loads are applied parallel to the axis $\mathrm{X}_{1}$ in the honeycomb structures (Honeycomb_0) failure of cells starts at the mid-section of the sample (Fig. 3). If the honeycomb geometry is loaded at $90^{\circ}$, failure bands are observed at oblique angles with $\mathrm{X}_{1}$. This is in accordance with previous research [1]. Lotus and Plateau samples follow the same trend of honeycombs, with oblique deformation bands, when loaded at $45^{\circ}$ and $90^{\circ}$, and localization of deformation at midsections when loaded at $0^{\circ}$. The failure modes are similar for the three geometries.

For each angle, the load-displacement curves are different for the three configurations. For the three geometrical arrangements, the higher loads were obtained when the configurations were loaded at the zero direction, while the lower loads were observed in $45^{\circ}$ orientations (Fig. 4).

For all three loading directions, both the strength and the stiffness are larger in the lotus configurations, followed by the Plateau and honeycomb arrangements (Tab. 1). The energy absorbed until the maximum load, scaled to the relative density, is higher for the lotus structure loaded at $90^{\circ}$, while has larger values for honeycomb structures in two directions, $0^{\circ}$ and $45^{\circ}$. 


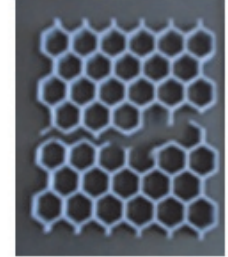

a)

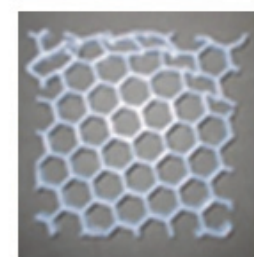

d)

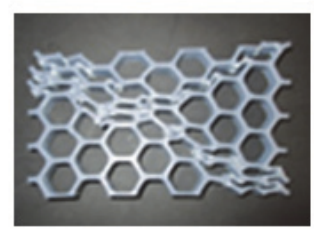

g)

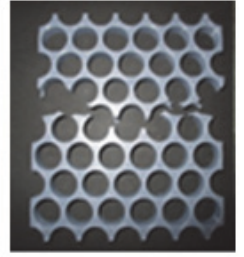

b)

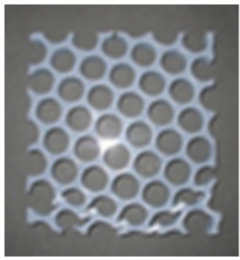

e)

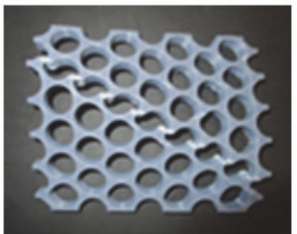

h)

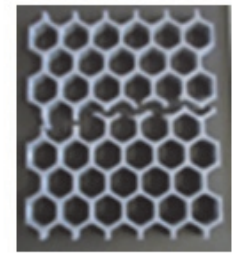

c)

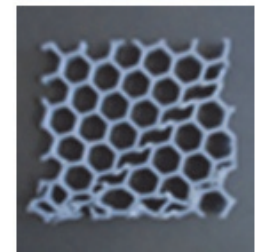

f)

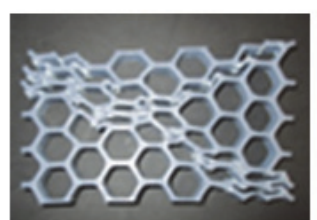

i)

Figure 3: Compression failure of geometries a) Honeycomb_0; b) Lotus_0; c) Plateau_0; d) Honeycomb_45; e) Lotus_45; f) Plateau_45; g) Honeycomb_90; h) Lotus_90; i) Plateau_90.

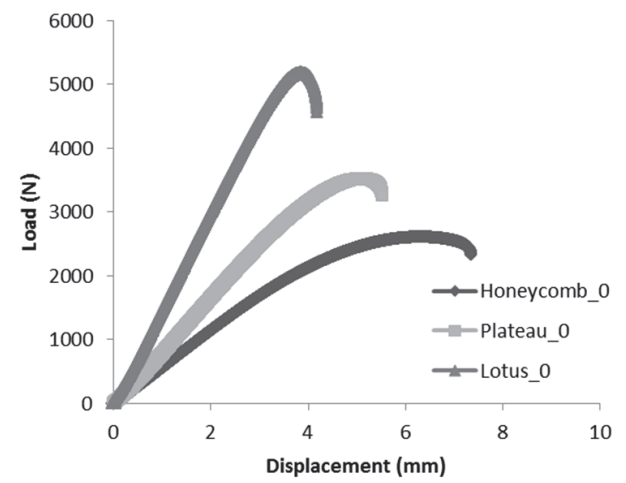

a)

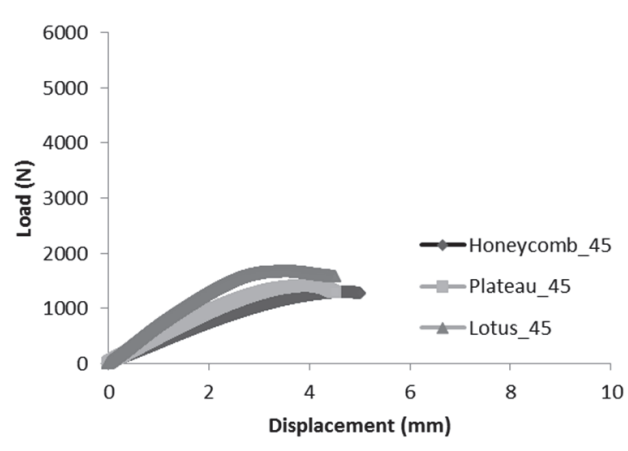

b)

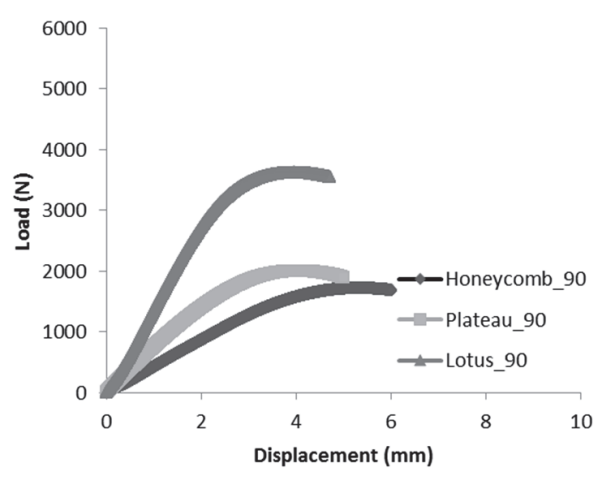

c)

Figure 4: Load-displacement curves for PLA samples Honeycomb, Lotus and Plateau in three loading directions, at angles of a) $0^{\circ}$, b) $45^{\circ}$ and c) $90^{\circ}$, obtained under experimental compression tests. 
Finite element results are shown as the von Mises stress distribution (Fig. 5), as well as load-displacement curves at the end of simulation tests (Fig. 6).

As can be seen from Fig. 5, the stress distribution is not uniform along the cellular arrangement, and one may infer that there will be localized deformation and subsequent failure at specific zones of the arrangement. The three arrangements loaded at $0^{\circ}$ show the possibility of deformation damage at mid sections, while in the other two cases $\left(45^{\circ}\right.$ and $\left.90^{\circ}\right)$, oblique bands are to be found. These findings are in accordance with experimental failure observations (Fig. 3), with the exceptions of Honeycomb_45 and Lotus_45. The failure modes differ with the loading direction either in experimental or simulation testing.

Honeycomb

0

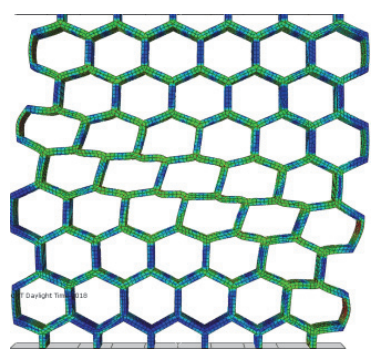

45

90
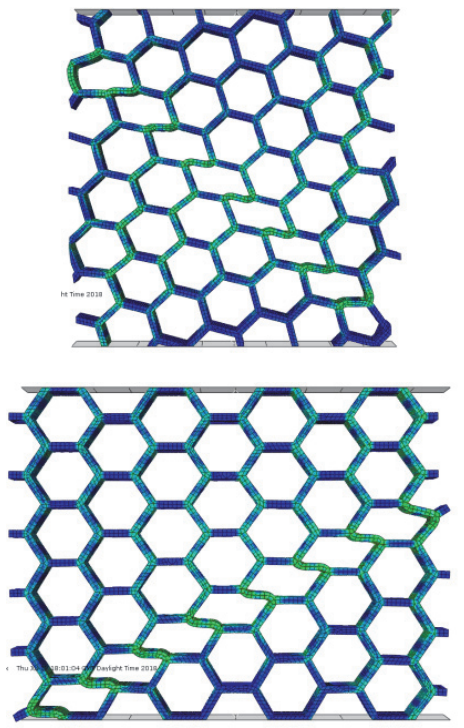

Lotus
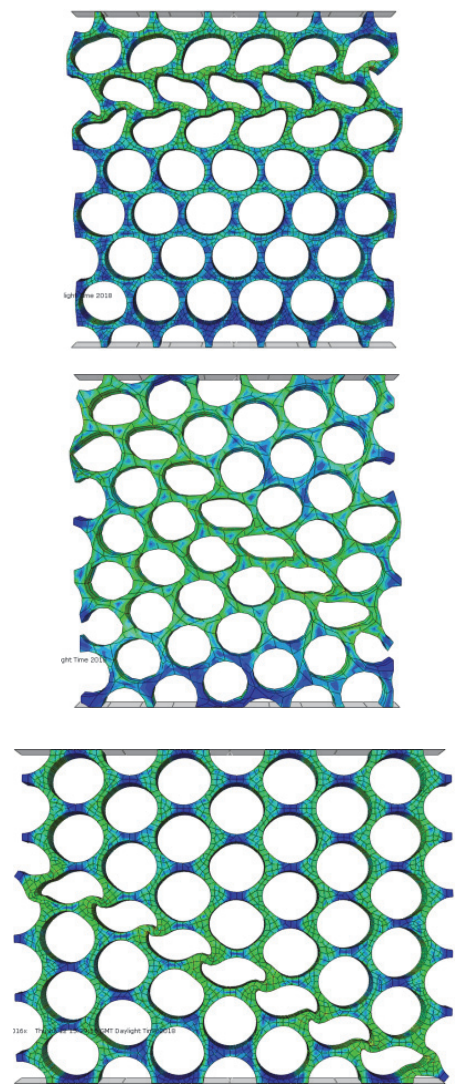

Plateau
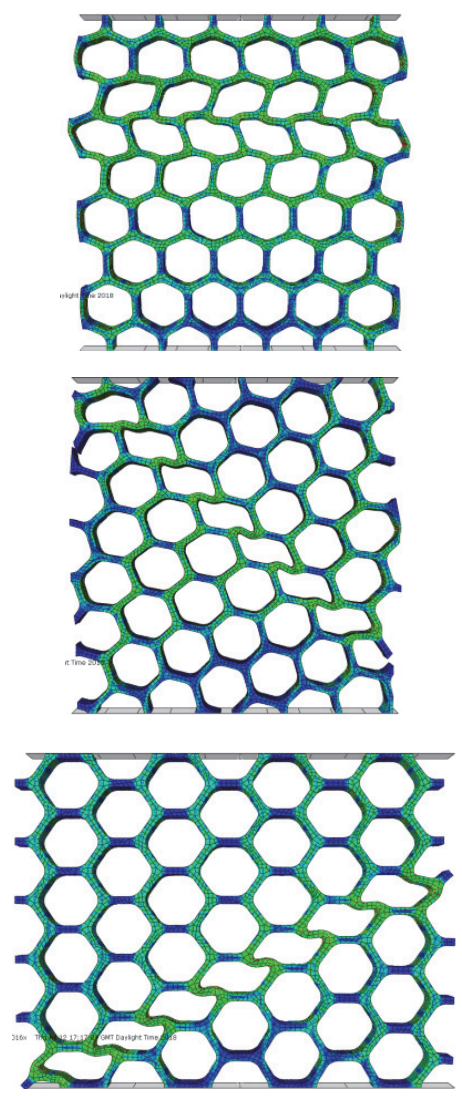

Figure 5: Finite element analysis of stress after compression of geometries Honeycomb, Lotus and Plateau configurations for PLA at directions 0, 45 and 90 (von Mises stress (MPa)).

The simulated force-displacement curves are shown in Fig. 6 for all the arrangements and the three loading directions. The shape of the curves was unchanged for all the geometries and loading directions with an initial linear part followed by a nonlinear region. For each angle the curves differ between configurations, namely in the initial slope and in maximum load attained (with the exception of Plateau_0 and Honeycomb_0). In the $0^{\circ}$ and $45^{\circ}$ conditions the same trend is verified, with the lotus configuration exhibiting the highest load, followed by the honeycomb geometry and finally by the Plateau arrangement. For $90^{\circ}$ case, lotus still shows the highest load.

A comparison of Fig. 4 with Fig. 6 shows that experimental and simulation curves exhibit similar shapes. However, there are differences in the load values between simulation and experimental results. The differences may be due to the nonhomogeneity of the experimental specimens obtained by FDM. In fact, although the infill parameter was taken to be 100 $\%$, thinner struts may be formed only by the contour lines and possess no infill material which give rise to compact struts. Also the presence of small air gaps or other defects can be expected. 


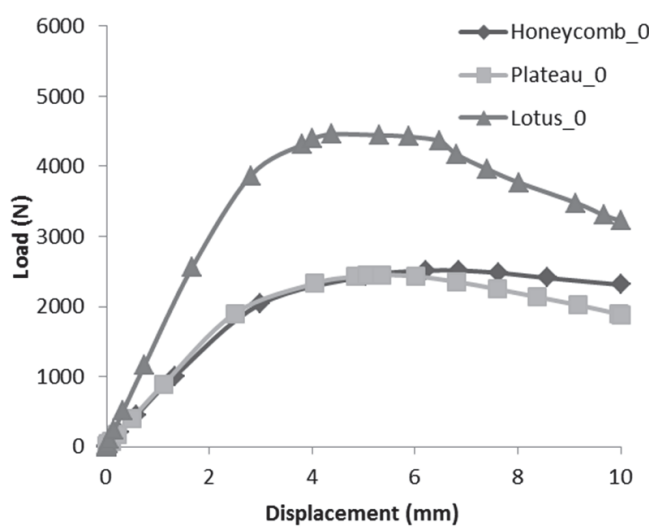

a)

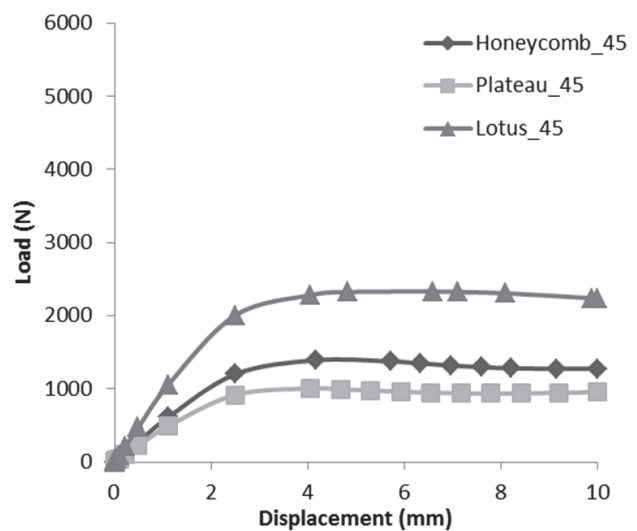

b)

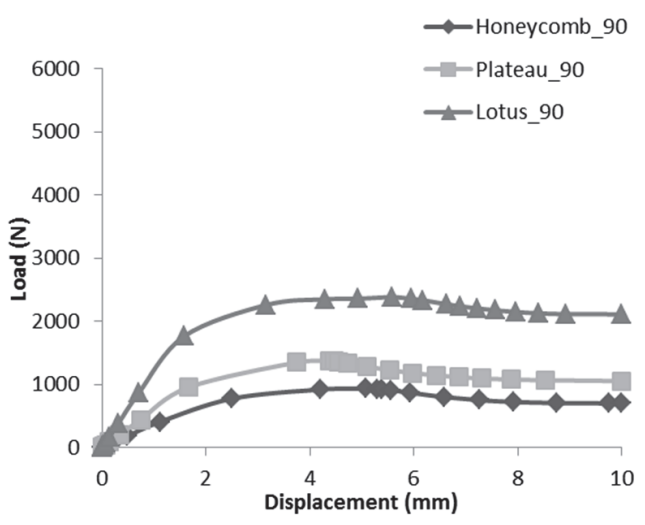

c)

Figure 6: Load-displacement curves for PLA samples honeycomb, lotus and Plateau in three loading directions, at angles of a) $0^{\circ}$, b) $45^{\circ}$ and c) $90^{\circ}$, obtained with finite element simulations.

\section{CONCLUSIONS}

S tructural panels made of sandwich composites are common in the fields of automotive and aerospace industries where the combination of high strength and stiffness with low weight are of utmost importance. In general the composite core is made of regular honeycomb structures. However, due to bending of cell walls, regular honeycombs present lower in-plane stiffness and strength. The current work pursuits new cell structure designs that lead to an improvement in the in-plane properties of the cellular structures.

Three core geometries, namely hexagonal honeycomb, lotus material, and hexagonal honeycomb with Plateau borders were numerically simulated. Fused deposition modelling enabled the fabrication of PLA specimens that were tested in compression for three different loading directions.

The failure modes differ with the loading direction but are similar for the three geometries. Failure zones present the same localization both in the experimental and in simulation data.

The effect of the geometry in the properties obtained in compression can be stated as follows: the lotus arrangement (which is considered to be a prismatic porous solid), gives rise to higher values of strength and stiffness in comparison with the Plateau configuration (that possesses an accumulation of material at vertices) and the conventional hexagonal honeycomb. With the preliminary results obtained in this paper, one may conclude that the Lotus configuration and in some cases the Plateau geometry as well, may be regarded as alternatives to regular honeycomb structures. 


\section{ACKNOWLEDGMENTS}

7 his work was supported by FCT, through IDMEC, under LAETA, project UID/EMS/50022/2019. Acknowledgements are due to João Cunha and Manuel Sardinha. Authors gratefully acknowledge the funding of Project POCI-01-0145-FEDER-016414, (FEDER and FCT).

\section{REFERENCES}

[1] Gibson, L.J., Ashby, M. (1997). Cellular Solids, structure and properties, Cambridge University Press.

[2] Bitzer, T. (1997). Honeycomb Technology: Material Design, Manufacturing Applications and Testing, Springer.

[3] Vinson, J.R. (1999). The Behavior of Sandwich Structures of Isotropic and Composite Materials, CRC Press.

[4] Zhu, F., Lu, G., Ruan, D., Wang, Z. (2010). Plastic Deformation, Failure and Energy Absorption of Sandwich Structures with Metallic Cellular Cores, Int. J. Prot. Struct., 1(4), pp. 507-41, DOI: 10.1260/2041-4196.1.4.507.

[5] Birman, V., Kardomateas, G.A. (2018). Review of current trends in research and applications of sandwich structures, Compos. Part B Eng., 142, pp. 221-240, DOI: 10.1016/j.compositesb.2018.01.027.

[6] Manalo, A., Aravinthan, T., Fam, A., Benmokrane, B. (2017). State-of-the-Art Review on FRP Sandwich Systems for Lightweight Civil Infrastructure, J. Compos. Constr., 21(1), pp. 04016068,

DOI: 10.1061/(ASCE)CC.1943-5614.0000729.

[7] Haldar, A.K., Zhou, J., Guan, Z. (2016). Energy absorbing characteristics of the composite contoured-core sandwich panels, Mater. Today Commun., 8, pp. 156-164, DOI: 10.1016/j.mtcomm.2016.08.002.

[8] Meraghni, F., Desrumaux, F., Benzeggagh, M.L. (1999). Mechanical behaviour of cellular core for structural sandwich panels, Compos. Part A Appl. Sci. Manuf., 30(6), pp. 767-779, DOI: 10.1016/S1359-835X(98)00182-1.

[9] Panda, B., Leite, M., Biswal, B.B., Niu, X., Garg, A. (2018). Experimental and numerical modelling of mechanical properties of 3D printed honeycomb structures, Measurement, 116, pp. 495-506, DOI: $10.1016 /$ j.measurement.2017.11.037.

[10] Imbalzano, G., Linforth, S., Ngo, T.D., Vee, P., Lee, S., Tran, P. (2018). Blast resistance of auxetic and honeycomb sandwich panels: Comparisons and parametric designs, Compos. Struct., DOI: 10.1016/j.compstruct.2017.03.018.

[11] Staal, R.A., Mallinson, G.D., Jayaraman, K., Horrigan, D.P.W. (2009). Predicting Failure Loads of Undamaged Sandwich Honeycomb Panels Subject to Bending, J. Sandw. Struct. Mater., 11(2-3), pp. 73-104, DOI: $10.1177 / 1099636209103557$.

[12] Gdoutos, E.E., Daniel, I.M., Wang, K.A., Abot, J.L. (2001). Nonlinear behavior of composite sandwich beams in three-point bending, Exp. Mech., DOI: 10.1007/BF02323195.

[13] Wahl, L., Maas, S., Waldmann, D., Zürbes, A., Frères, P. (2012). Shear stresses in honeycomb sandwich plates: Analytical solution, finite element method and experimental verification, J. Sandw. Struct. Mater., 14(4), pp. 449-468, DOI: $10.1177 / 1099636212444655$.

[14] Othman, A.R., Barton, D.C. (2008). Failure initiation and propagation characteristics of honeycomb sandwich composites, Compos. Struct., 85(2), pp. 126-138, DOI: 10.1016/j.compstruct.2007.10.034.

[15] Ingrole, A., Hao, A., Liang, R. (2017). Design and modeling of auxetic and hybrid honeycomb structures for in-plane property enhancement, Mater. Des., 117, pp. 72-83, DOI: 10.1016/j.matdes.2016.12.067.

[16] Han, B., Qin, K., Yu, B., Wang, B., Zhang, Q., Lu, T.J. (2016). Honeycomb-corrugation hybrid as a novel sandwich core for significantly enhanced compressive performance, Mater. Des., 93, pp. 271-282, DOI: $10.1016 /$ j.matdes.2015.12.158.

[17] Rong, Y., Liu, J., Luo, W., He, W. (2018). Effects of geometric configurations of corrugated cores on the local impact and planar compression of sandwich panels, Compos. Part B Eng., 152, pp. 324-335, DOI: $10.1016 /$ j.compositesb.2018.08.130.

[18] Wang, Z., Li, Z., Xiong, W. (2019). Numerical study on three-point bending behavior of honeycomb sandwich with ceramic tile, Compos. Part B Eng., 167, pp. 63-70, DOI: 10.1016/j.compositesb.2018.11.108.

[19] Jin, X., Wang, Z., Ning, J., Xiao, G., Liu, E., Shu, X. (2016). Dynamic response of sandwich structures with graded auxetic honeycomb cores under blast loading, Compos. Part B Eng., 106, pp. 206-217, DOI: $10.1016 /$ j.compositesb.2016.09.037.

[20] Uzal, A., Sonmez, F.O., Oz, F.E., Cinar, K., Ersoy, N. (2018). A composite sandwich plate with a novel core design, Compos. Struct., 193, pp. 198-211, DOI: 10.1016/j.compstruct.2018.03.047.

[21] Ullah, I., Brandt, M., Feih, S. (2016). Failure and energy absorption characteristics of advanced 3D truss core 
structures, Mater. Des., 92, pp. 937-948, DOI: 10.1016/j.matdes.2015.12.058.

[22] Feng, L.-J., Wei, G.-T., Yu, G.-C., Wu, L.-Z. (2019). Underwater blast behaviors of enhanced lattice truss sandwich panels, Int. J. Mech. Sci., 150, pp. 238-246, DOI: 10.1016/j.ijmecsci.2018.10.025.

[23] Araújo, H., Leite, M., Ribeiro, A., Deus, A., Reis, L., Vaz, M.F. (2019). The effect of geometry on the flexural properties of cellular core structures, Proc. Inst. Mech. Eng. Part L J. Mater. Des. Appl., 233(3), pp. 338-347, DOI: $10.1177 / 1464420718805511$.

[24] Ronan, W., Deshpande, V.S., Fleck, N.A. (2016). The tensile ductility of cellular Solids: The role of imperfections, Int. J. Solids Struct., 102-103, pp. 200-213, DOI: 10.1016/j.ijsolstr.2016.10.004.

[25] Gomez-Gras, G., Jerez-Mesa, R., Travieso-Rodriguez, J.A., Lluma-Fuentes, J. (2018). Fatigue performance of fused filament fabrication PLA specimens, Mater. Des., 140, pp. 278-285, DOI: 10.1016/j.matdes.2017.11.072.

[26] Croccolo, D., De Agostinis, M., Olmi, G. (2013). Experimental characterization and analytical modelling of the mechanical behaviour of fused deposition processed parts made of ABS-M30, Comput. Mater. Sci., 79, pp. 506-518, DOI: 10.1016/j.commatsci.2013.06.041.

[27] Turner, B.N., Strong, R., Gold, S.A. (2014). A review of melt extrusion additive manufacturing processes: I. Process design and modelling, Rapid Prototyp. J., 20(3), pp. 192-204, DOI: 10.1108/RPJ-01-2013-0012.

[28] Leite, M., Varanda, A., Ribeiro, A.R., Silva, A., Vaz, M.F. (2018). Mechanical properties and water absorption of surface modified ABS 3D printed by fused deposition modelling, Rapid Prototyp. J., 24(1), pp. 195-203, DOI: $10.1108 /$ RPJ-04-2016-0057.

[29] Polzin, C., Spath, S., Seitz, H. (2013). Characterization and evaluation of a PMMA-based 3D printing process, Rapid Prototyp. J., 19, pp. 37-43, DOI: 10.1108/13552541311292718.

[30] Vaezi, M., Seitz, H., Yang, S. (2013). A review on 3D micro-additive manufacturing technologies, Int. J. Adv. Manuf. Technol., , pp. 1721-1754, DOI: 10.1007/s00170-012-4605-2.

[31] Wu, W., Geng, P., Li, G., Zhao, D., Zhang, H., Zhao, J. (2015). Influence of layer thickness and raster angle on the mechanical properties of 3D-printed PEEK and a comparative mechanical study between PEEK and ABS, Materials (Basel)., 8(9), pp. 5834-5846, DOI: 10.3390/ma8095271.

[32] Farah, S., Anderson, D.G., Langer, R. (2016). Physical and mechanical properties of PLA, and their functions in widespread applications - A comprehensive review, Adv. Drug Deliv. Rev., 107, pp. 367-392, DOI: $10.1016 /$ j.addr.2016.06.012.

[33] Fernandes J, Deus AM, Reis L, Vaz MF, L.M. (2018).Study of the influence of 3D printing parameters on the mechanical properties of PLA. 3rd international conference on progress in additive manufacturing (Pro-AM 2018), Singapore. 